\title{
Effect of the $\mathrm{Ba} / \mathrm{Sr}$ ratio on the optical properties of phosphate laser glass
}

\author{
A.S.Popov ${ }^{1}$, A.V.Uklein ${ }^{1}$, A.N.Zaderko $^{2}$, \\ V.A.Kozhanov ${ }^{2}$, V.V.Lisnyak ${ }^{2}$, V.Ya.Gayvoronsky ${ }^{1}$ \\ ${ }^{1}$ Institute of Physics, National Academy of Sciences of Ukraine, \\ 46 Nauki Ave., 03680 Kyiv, Ukraine \\ ${ }^{2}$ Chemical Faculty, T.Shevchenko National University of Kyiv, \\ 62a Volodymyrska Str., 01601 Kyiv, Ukraine
}

\section{Received March 16, 2015}

\begin{abstract}
Nonlinear optical (NLO) approach was utilized for the laser phosphate glasses characterization, being prepared by the molar substitution of $\mathrm{Ba}^{2+}$ for $\mathrm{Sr}^{2+}$ at a fixed ratio of other components in a mixture of $\mathrm{Ba}_{1-x} \mathrm{O} / \mathrm{Sr}_{x} \mathrm{O}-\mathrm{P}_{2} \mathrm{O}_{5}-\mathrm{Al}_{2} \mathrm{O}_{3}-\mathrm{B}_{2} \mathrm{O}_{3}-\mathrm{RE}_{2} \mathrm{O}_{3}$ (RE : Nd, La). The optical characterization of the glasses was provided by optical and FTIR spectroscopy and elastic scattering indicatrices analyses. It was shown that an efficiency of the photoinduced absorption/bleaching depends on the substitution $\mathrm{Ba}^{2+}-\mathrm{Sr}^{2+}$ level $x$ due to the self-action of pulsed and CW laser radiation at wavelength $1064 \mathrm{~nm}$. The proposed technique can be applied for the oxygen stoichiometry diagnostics for laser phosphate glasses. For the $x=0.25$ composition it was obtained UV-vis range absorption and elastic scattering reduction within the lowest efficiencies of the NLO absorptive response under pulsed and CW laser excitation at wavelength $1064 \mathrm{~nm}$. Such optical properties improvement was achieved by both the substitution level choice modification and the purification of the initial reagents.
\end{abstract}

Keywords: Laser phosphate glasses, Ba/Sr ratio, photoinduced absorption, cubic nonlinear optical susceptibility, UV-visible and FTIR spectra, elastic scattering indicatrix.

\footnotetext{
Проведена характеризация нелинейно-оптического (НЛО) отклика фосфатного лазерного стекла, изготовленного путем замещения ионов $\mathrm{Ba}^{2+} \mathrm{Ha} \mathrm{Sr}^{2+}$ при фиксированном составе других компонент в растворе замещения $\mathrm{Ba}_{1-x} \mathrm{O} / \mathrm{Sr}_{x} \mathrm{O}-\mathrm{P}_{2} \mathrm{O}_{5}-\mathrm{Al}_{2} \mathrm{O}_{3}-\mathrm{B}_{2} \mathrm{O}_{3}-$ $\mathrm{RE}_{2} \mathrm{O}_{3}(\mathrm{RE}: \mathrm{Nd}$, La), совместно со спектральным анализом в видимом и ИК диапазонах и исследованием индикатрис упругого рассеяния света. Показано, что әффективность процессов фотоиндуцированного поглощения/просветления зависит от степени замещения $\mathrm{Ba}^{2+}-\mathrm{Sr}^{2+}-x$ при самовоздействии непрерывного и импульсного лазерного излучения с длиной волны 1064 нм. Предложенная методика может быть применена для диагностики стехиометрии по кислороду в фосфатных лазерных стеклах. Для состава с $x=0.25$ наблюдалось уменьшение спектрального поглощения и упругого рассеяния света при минимальной әффективности абсорбционного НЛО отклика в условиях импульсного и непрерывного лазерного возбуждения на длине волны 1064 нм. В результате получено улучшение оптических свойств фосфатного стекла путем подбора степени замещения и очистки первичных реагентов.
}

Вплив вмісту $\mathrm{Ba} / \mathrm{Sr}$ на оптичні властивості фосфатного лазерного скла. O.C.Попов, А.В.Уклеін, А.М.Задерко, В.О.Кожанов, В.В.Лісняк, В.Я.Гайворонсъкий.

Проведено характеризацію нелінійно-оптичного (НЛО) відгуку фосфатного лазерного скла, що було виготовлено шляхом заміщення іонів $\mathrm{Ba}^{2+} \mathrm{Ha} \mathrm{Sr}^{2+}$ при фіксованому вмісті інших компонент у розчині заміщення $\mathrm{Ba}_{1-x} \mathrm{O} / \mathrm{Sr}_{x} \mathrm{O}-\mathrm{P}_{2} \mathrm{O}_{5}-\mathrm{Al}_{2} \mathrm{O}_{3}-\mathrm{B}_{2} \mathrm{O}_{3}-$ $\mathrm{RE}_{2} \mathrm{O}_{3}(\mathrm{RE}: \mathrm{Nd}, \mathrm{La})$, разом із спектральним аналізом у видимому та IЧ діапазонах та 
дослідженням індикатрис пружного розсіювання світла. Показано, що ефективність процесів фотоіндукованого поглинання/просвітлення залежить від ступеня заміщення $\mathrm{Ba}^{2+}-\mathrm{Sr}^{2+}-x$ при самовпливі неперервного та імпульсного лазерного випромінювання 3 довжиною хвилі 1064 нм. Запропонована методика може бути застосована для діагностики стехіометрії за киснем у фосфатному лазерному склі. Для складу $x=0.25$ спостерігалося зменшення спектрального поглинання та пружного розсіювання світла разом 3 мінімальною ефективністю абсорбційного НЛО відгуку при імпульсному та неперервному лазерному збудженні на довжині хвилі 1064 нм. В результаті отримано покращення оптичних властивостей фосфатного скла шляхом підбору ступеня заміщення та очищення первинних реагентів.

\section{Introduction}

Glassy materials with a high quantum yield of the luminescence and improved thermo-optical characteristics are used for the production of large-sized workpieces for the laser application. These optical workpieces show a low crystallization propensity and have reduced efficiency of the refractive nonlinear response. A number of phosphate-based glasses of such a type are known for nowadays [1-7]. Among them are the optical phosphate glasses that composed of (in mass \% ) 55-65 $\mathrm{P}_{2} \mathrm{O}_{5}, 8-12$ $\mathrm{BaO}, 10-15 \mathrm{~K}_{2} \mathrm{O}, 1-4 \mathrm{SiO}_{2}, 5-10 \mathrm{Al}_{2} \mathrm{O}_{3}, 2-6$ $\mathrm{B}_{2} \mathrm{O}_{3}, 0.1-4.5 \mathrm{Nd}_{2} \mathrm{O}_{3}$. These optical glasses have high values of stimulated transitions cross sections, of about $3.5 \cdot 10^{-20} \mathrm{~cm}^{2}$, and high luminescence decay time. However, they demonstrate a low absorption at the wavelength of $1053 \mathrm{~nm}$, which magnitude is less than $0.001 \mathrm{~cm}^{-1}$ [3]. The improvement of the glasses characteristics can be reached with: (i) the reduction of concentration quenching of luminescence, which depends on the distances between $\mathrm{Nd}$ atoms in a glass matrix; (ii) reduction of the photoinduced absorption efficiency [7] at high radiation densities; (iii) decreasing the propensity to crystallization and (iv) lowering the content of colouring impurities. These changes could be done, at the stage of the glass preparation, through convenient chemical methods. These methods direct on the changing the composition of these glasses and the purity of raw materials that are used at the glass production stage.

There two types of substitution can be performed in such glasses: (1) the substitution of $\mathrm{Ba}$ by $\mathrm{Sr}$ ions that controls oxygen stoichiometry and (2) $\mathrm{Nd}^{3+}$ by $\mathrm{La}^{3+}$ ions that reduces $\mathrm{Nd}_{2} \mathrm{O}_{3}$ fraction. The last one improves the possibility for the optical characterization due to the reduction of the absorbance and emission yield without structural properties modification, being determined by the small difference in ionic radii of the rare earth (RE) ions: $0.98 \AA\left(\mathrm{Nd}^{3+}\right)$ and $1.03 \AA\left(\mathrm{La}^{3+}\right)$ with the coordination number (CN) of $\mathrm{CN}_{\mathrm{RE}-\mathrm{O}}=8$ [8]. At the same time, the substitution of $\mathrm{Ba}^{2+}$ for $\mathrm{Sr}^{2+}$ decreases the crystallisation index of the glasses. Since the values of the radii are $1.42 \AA$ for $\mathrm{Ba}^{2+}$ at $\mathrm{CN}_{\mathrm{Ba}-\mathrm{O}}=8$ and $1.26 \AA$ for $\mathrm{Sr}^{2+}$ at $\mathrm{CN}_{\mathrm{Sr}-\mathrm{O}}=6$, the difference in the effective cations ionic radii supports an amorphization. The crystallisation index reduction is in a good agreement with experimental data [9] because the packing density of the $\mathrm{Ba}_{1-x} \mathrm{O} / \mathrm{Sr}_{x} \mathrm{O}-\mathrm{P}_{2} \mathrm{O}_{5}-\mathrm{Al}_{2} \mathrm{O}_{3}-\mathrm{B}_{2} \mathrm{O}_{3}-\mathrm{Nd}_{2} \mathrm{O}_{3} / \mathrm{La}_{2} \mathrm{O}_{3}$ phosphate glasses $\left(\mathrm{Ba}_{1-x} \mathrm{Sr}_{x} \mathrm{gl}\right)$ deviates from the linear dependence versus the molar ratio of Sr/Ba. It causes the alkaline earth metaloxygen polyhedra distortion similarly to that observed in [10], and the transition from the glass net that is built up with $\mathrm{BaO}_{8}$ polyhedrons to that formed with $\mathrm{SrO}_{6}$ octahedrons. Such modification effects on the distance between the nearest neighbour $\mathrm{La} / \mathrm{Nd}-\mathrm{La} / \mathrm{Nd}$ atomic pairs that can drastically impact on optical properties of the glasses.

In this paper we report the effect of the $\mathrm{Ba} / \mathrm{Sr}$ ratio on the optical properties of the substituted phosphate laser optical glasses $\mathrm{Ba}_{1-x} \mathrm{Sr}_{x} \mathrm{gl}$ studied in the whole substitution range $x=0-1$. It was performed with the molar fraction $x$ increment of 0.25 . The glass samples were prepared from the initial reagents purified by specially elaborated chemical techniques. We have applied the nonlinear optical (NLO) response characterization within the spatial beam profile analysis technique [11], which works due to the self-action effect of the continuous wave (CW) and pulsed laser radiation at wavelength $1064 \mathrm{~nm}(1.17 \mathrm{eV})$. The approach is based on successful application of the technique for substitution level of the Lu by Gd atoms characterization in the oxyorthosilicates single crystals [12]. It demonstrated a high sensitivity to the oxygen stoichiometry controlled by $\mathrm{Sr} / \mathrm{Ba}$ content in laser phosphate glasses.

\section{Experimental}

\subsection{Initial materials}

Reagent grade Sigma-Aldrich chemicals: $\mathrm{Ba}\left(\mathrm{NO}_{3}\right)_{2}, \quad \mathrm{Sr}\left(\mathrm{NO}_{3}\right)_{2}, \quad\left(\mathrm{NH}_{4}\right)_{2} \mathrm{HPO}_{4} \quad$ and 
$\mathrm{KH}_{2} \mathrm{PO}_{4}$, were purified to prepare a high purity analytical reagent grade chemicals; Onyxmet (Olsztyn, Poland) products: $\mathrm{La}_{2} \mathrm{O}_{3}$ "D" and $\mathrm{Nd}_{2} \mathrm{O}_{3}$ "E" was used as is. The following three methods were used for the purification: (i) the complexing of colouring impurities, ppms of $d$-metal ions, $\mathrm{Fe}, \mathrm{Cu}$, $\mathrm{Co}, \mathrm{Ni}, \mathrm{Mo}, \mathrm{V}, \mathrm{Cr}$ and $\mathrm{Mn}$, to form stabile diethyldithiocarbomate (DDC) complexes that adsorbs on non-oxidized activated carbon (AC) derived from wood with further deashed with $\mathrm{HF}$ and $\mathrm{HCl}$ solution, (ii) the adsorption of the metal ions by the surface of the respective oxidized $\mathrm{AC}$, and (iii) $\mathrm{Ba}\left(\mathrm{NO}_{3}\right)_{2}, \mathrm{Sr}\left(\mathrm{NO}_{3}\right)_{2}$ reagents recrystallization with the partial precipitation of carbonates that occlude respective $d$-metals ions. $\mathrm{SiO}_{2} \cdot \mathrm{nH}_{2} \mathrm{O}$ was prepared from Dynasylan ${ }^{\circledR} \mathrm{A}$, tetraethyl-orthosilicate, that additionally was purified by distillation in the presence of oxidized AC. This purified product was subjected to a hydrolysis in doubledistilled water. A small quantity of ammonia (puriss.) was added to the water, as the hydrolysis catalyst. The obtained product was separated and then dried. The content of $\mathrm{SiO}_{2}$ in the product of the hydrolysis was determined by thermogravimetry using an apparatus reported in [13]. The analytical control of the purity was done by the spectrophotometric analysis using an extraction of DDC-complexes with $\mathrm{CHCl}_{3}$. As the purification result, the total concentration of colouring impurities in each product is lowered to $0.1-2 \mathrm{ppm}$ from $20-5 \mathrm{ppm}$ for the each of the ions. Boria and alumina used for the glasses preparation are purity reagent grade chemicals of the Federal State Unitary Enterprise IREA (Moscow, Russia).

The obtained purified powders were used for the preparation of glass samples that are based on the composition (in mass \%): $\mathrm{P}_{2} \mathrm{O}_{5}-58, \mathrm{BaO}-12, \mathrm{~K}_{2} \mathrm{O}-13, \mathrm{SiO}_{2}-2$, $\mathrm{Al}_{2} \mathrm{O}_{3}-8, \mathrm{~B}_{2} \mathrm{O}_{3}-4, \mathrm{Nd}_{2} \mathrm{O}_{3}-0.5, \mathrm{La}_{2} \mathrm{O}_{3}-2.5$. To prepare the $\mathrm{Sr} / \mathrm{Ba}$ glasses, the $\mathrm{BaO}$ component in the composition of a butch mixture, which is used for the glass preparation, was partially or completely substituted for SrO. A sum of the molar composition of the alkaline earth oxides is kept fixed to the value equivalent to 12 mass $\%$ of $\mathrm{BaO}$. The glasses were obtained by the components melting. The prepared glass samples are designated as $\mathrm{Ba}_{1-x} \mathrm{Sr}_{x} \mathrm{gl}$ and $x=0$, $0.25,0.75,0.50$ and 1.0 . The value of $x$ denotes the molar fraction of strontium in the glass as regard to the content of $\mathrm{Ba}$.

\subsection{Preparation of glasses samples}

A typical preparation of glass sample was performed as follows. Appropriate amounts of the initial materials, as per the composition of glasses, were properly weighed. A batch mixture of the initial components $(20 \mathrm{~g})$ was wetted with doubledistilled water, as mixing medium, mixed in a new porcelain mortal and transferred into a $40 \mathrm{ml}$ transparent quartz crucible. The mixture was heated in a programmable electric resistance furnace, which enclosed volume is made from an alundum tube. The heating was conducted at the slow heating rate up to $1000^{\circ} \mathrm{C}$ for $4 \mathrm{~h}$. After that, the mixture was heated up to $1330^{\circ} \mathrm{C}$ for $2 \mathrm{~h}$ and periodically mixed with a quartz rod. It should be noticed that the melting temperatures for different compositions were in the range of $1050-1330^{\circ} \mathrm{C}$. The melt was maintained at $1330^{\circ} \mathrm{C}$ in the furnace for $10 \mathrm{~min}$ for refining and homogenization and then it was cooled and poured into a cast-iron mould preheated up to $400^{\circ} \mathrm{C}$ and pressed by a plate. This cast iron mould with a glass within was leaved to get slowly cooled, with a $5^{\circ} \mathrm{C}$ per minute rate, and after that the resulted glass was annealed in a muffle furnace at the temperature of $450^{\circ} \mathrm{C}$ for $6 \mathrm{~h}$. The annealing was performed to remove the residual stresses due to temperature gradient, which is produced by rapid cooling. Annealed glass samples were parallel cut to obtain plates of $1 \mathrm{~mm}$ thin.

\subsection{Samples characterization}

Pycnometric density of the glasses $(\rho)$ was determined by weighting, similarly as in ASTM D854 [14], in air and in hexane at $23^{\circ} \mathrm{C}$. A non-polar hexane medium was used instead of water to prevent dissolution. The powdered glass samples were mixed with $\mathrm{KBr}$ powder and then pressed.

Fourier Transformed Infrared (FTIR) spectroscopy. The pellets were examined by using a Thermo Nicollet Nexus 470 FTIR spectrometer. FTIR spectra were recorded in the wavenumbers range of $400-1600 \mathrm{~cm}^{-1}$ at $25^{\circ} \mathrm{C}$ using a 1026 scans regime.

Ultraviolet-visible (UV-Vis) spectroscopy. UV-VIS spectra of the glasses were recorded by means of UV-VIS spectrophotometer (Shimadzu UV-2700 instrument) by using $1 \mathrm{~nm}$ scan step.

Empirical estimation of optical properties of glasses. Optical characteristics of glass materials, in particular, linear and nonlinear refractions, depend on the elec- 
tron polarizability of the medium under irradiation [15]. So, the empirical approach proposed by Duffy and Ingram [16] is widely used to bind the chemical composition changes with the optical properties of glasses [16-18]. In this paradigm, the average molar refraction $\left(R_{m}\right)$ was calculated from the equation:

$$
\begin{gathered}
R_{m}=p R_{i}+q R\left(\mathrm{O}^{2-}\right)= \\
=2.52\left(p \sum \alpha_{i}+q \alpha\left(\mathrm{O}^{2-}\right)\right),
\end{gathered}
$$

where $\alpha_{i}$ and $\alpha\left(\mathrm{O}^{2-}\right)$ are the molar polarization ability of cation taken form [8] and anion in a glass matrix, $R_{i}$ and $R\left(\mathrm{O}^{2-}\right)$ are the ionic constituents of the refraction for cations and oxygen anion, $p$ and $q$ are the cation and anion molar coefficients in the glass formula. The theoretic optical basicity $\left(\Lambda_{t h}\right)$, which is sensitive to changes at chemical composition of glass, was estimated through the formula:

$$
\Lambda_{t h}=\sum \Lambda_{i} \chi_{i},
$$

where $\Lambda_{i}$ and $\chi_{i}$ are the optical basicity and the molar part of $i$-component. The polarizability of oxygen ions $\left(\alpha\left(\mathrm{O}^{2-}\right)\right)$ was calculated through a simple relation with $\Lambda_{t h}$ [19]

$$
\alpha\left(\mathrm{O}^{2-}\right)=\left(1-\Lambda_{t h} / 1.67\right)^{-1} .
$$

Since the linear and nonlinear refractive indexes correlates, the Goldhammer-Herzfeld metallization criterion (GH), which characterizes the covalence of a glass medium, was found from the formula:

$$
G H=\left(1-\frac{R_{m}}{V_{m}}\right)=\left(1-\frac{n_{0}^{2}-1}{n_{0}^{2}+2}\right),
$$

where $V_{m}$ is the molar volume, $n_{0}$ is the linear refraction index. The ionic packing ratio $\left(V_{p}\right)$ of the glass host- a ratio of specific ion total volume per mole to the molar volume, was calculated, in approximation that each ion in the glass was a rigid sphere, from the equation:

$$
V_{p}=\left(\sum_{i} \frac{4}{3} \pi r_{i}^{3} n_{i} N_{A}\right) V_{m}^{-1},
$$

where $r$ is the ionic radius, $n$ is the molar fraction, $N_{A}$ is the Avogadro number, $M$ is the molar weight, and $\rho$ is the pycnometric density of the glass host.
Elastic scattering indicatrix. The optical elastic scattering indicatrices into forward hemisphere of the phosphate glasses were measured under the CW DPSS laser irradiation at $1064 \mathrm{~nm}$. The scattered light was registered by the CCD camera (ATiK 16 IC-HS with pixel size $7.4 \times 7.4 \mu^{2}$ and $640 \times 480$ image resolution) at the distance of $39.2 \mathrm{~cm}$ from the sample. The elastic scattering losses into forward hemisphere were estimated within the approach described in [20].

Nonlinear optical characterization. The absorptive NLO response was studied by the photoinduced total transmittance variation due to the self-action of the pulsed and CW laser radiation at wavelength $1064 \mathrm{~nm}$ $(1.17 \mathrm{eV})$ that can induce resonant two-photon absorption process. The measurements were performed according to the technique described in [11]. For the pulsed excitation we utilized the radiation of the mode-locked $\mathrm{Nd}^{3+}:$ YAG laser with pulsewidth $42 \mathrm{ps}$ (FWHM) and repetition rate $50 \mathrm{~Hz}$. For CW excitation we applied DPSS laser with peak output power $\sim 20 \mathrm{~mW}$. The samples were positioned at the input aperture $(1 \mathrm{~cm}$ diameter $)$ of the photodiode in order to avoid impact of the scattering extinction losses. We have thoroughly checked the reversibility of the photoinduced transmittance variation with rise/reduction of the input laser radiation intensity.

Fitting the experimental data of the total transmittance versus the peak laser intensity $I$ according to the route described in [21] provides estimation of the photoinduced absorption variation $\Delta \alpha$ magnitudes that is proportional to the imaginary part of the cubic NLO susceptibility $\Delta \alpha \sim \operatorname{Im}\left(\chi^{(3)}\right) I$.

\section{Results and discussion}

\subsection{Empirical estimation of optical prop- erties}

The $\mathrm{Ba}_{1-x} \mathrm{Sr}_{x} \mathrm{gl}$ pycnometric density, optic and physic characteristics, which are estimated from (1-5), are listed in Table 1 . The values of $R_{m}$ and $\alpha\left(\mathrm{O}^{2-}\right)$ decrease with an increase of the $\mathrm{Sr}$ content. GH criterion possesses a significant reduction of the magnitudes up to 0.762 for the laser glasses with $x \geq 0.5$ that show the highest value of a media covalence. The maximal values of $\rho$ and $V_{m}$ are characterized the pure Ba glass. The value of $\Lambda_{t h}$ decreases monotonously from Ba-based to Sr-based glass. 
Table 1. The estimated optical and physical characteristics of the $\mathrm{Ba}_{1-\chi} \mathrm{Sr}_{\chi} \mathrm{gl}$ glasses with different $\mathrm{Ba} / \mathrm{Sr}$ ratio, $\Lambda_{t h}$ - the theoretic optical basicity, $\alpha\left(\mathrm{O}^{2-}\right)$ - the polarizability of oxygen ions, $R_{m}$ - the average molar refraction, $V_{m}$ - the molar volume, $V_{p}$ - the ionic packing ratio of the glass host, $\rho$ - the pycnometric density, GH - the Goldhammer-Herzfeld metallization criterion

\begin{tabular}{||c|c|c|c|c|c||}
\hline \hline Sr content, $x$ & 0.0 & 0.25 & 0.50 & 0.75 & 1.0 \\
\hline$\Lambda_{t h}$ & 0.639 & 0.638 & 0.637 & 0.636 & 0.634 \\
\hline$\alpha\left(\mathrm{O}^{2-}\right), \mathrm{cm}^{3} / \mathrm{mol}$ & 1.620 & 1.618 & 1.616 & 1.614 & 1.613 \\
\hline$R_{m}, \mathrm{~cm}^{3} / \mathrm{mol}$ & 4.788 & 4.770 & 4.753 & 4.736 & 4.718 \\
\hline$V_{m}, \mathrm{~m}^{3}$ & 0.027 & 0.024 & 0.020 & 0.020 & 0.020 \\
\hline${ }^{*} V_{p}, \%$ & 68.9 & 59.0 & 50.1 & 49.0 & 49.6 \\
\hline$\rho, \mathrm{g} / \mathrm{cm}^{3}$ & 3.310 & 2.930 & 2.470 & 2.400 & 2.410 \\
\hline $\mathrm{GH}$ & 0.822 & 0.801 & 0.762 & 0.763 & 0.764 \\
\hline \hline
\end{tabular}

"Note: $\mathrm{CN}_{\mathrm{Ba}-\mathrm{O}}=8$ and $\mathrm{CN}_{\mathrm{Sr}-\mathrm{O}}=6$.

\subsection{UV-Vis spectroscopy}

The absorption spectra of the studied glasses are presented in Fig. 1 with the most intensive seven $\mathrm{Nd}^{3+}$ bands centred at about $805,744,684,583,525,428$, and $355 \mathrm{~nm}$, which are assigned as in [22]. The absorption bands originate from the ground ${ }^{4} I_{9 / 2}$ state due to $4 f-4 f$ orbital electronic transitions with wave functions localized within the single $\mathrm{Nd}^{3+}$ ion. They are forbidden in the electric dipole approximation by quantum mechanical selection rules, which, however, are relaxed via local field-induced intermixing of the $f$ states with higher electronic configurations. The shielding of the $4 f$ electrons by the outer complete $5 s$ and $5 p$ shells results in a quite identical and practically independent position from the minor changes at $\mathrm{Nd}^{3+}$ volume concentration with the $\mathrm{Ba} / \mathrm{Sr}$ ratio.

On the other hand, the substitution of $\mathrm{Ba}$ with Sr effects on the structure and properties of the glass matrix. The ionic packing ratio varies slightly for phosphate glasses by changing network modifier ion; therefore, it is difficult to clarify the effect of ionic packing ratio $V_{p}$ on the optical spectra. The results of studies suggest that $\mathrm{Nd}^{3+}$ ions are incorporated into certain sites to break $\mathrm{P}=\mathrm{O}$ bonds in phosphate glasses.

It should be noted that the glass containing $\mathrm{Ba}$ without $\mathrm{Sr}(x=0.0)$ is the most transparent among others. The rise of the substitution level up to $x \leq 0.75$ leads to the monotonic darkening of the samples. For the glass containing $\mathrm{Sr}$ without $\mathrm{Ba}(x=1.0)$ the spectral transmittance of the sample are between the corresponding ones for the glasses with $x=0.25$ and 0.50 .

We have performed NLO characterization of the samples at the laser radia-

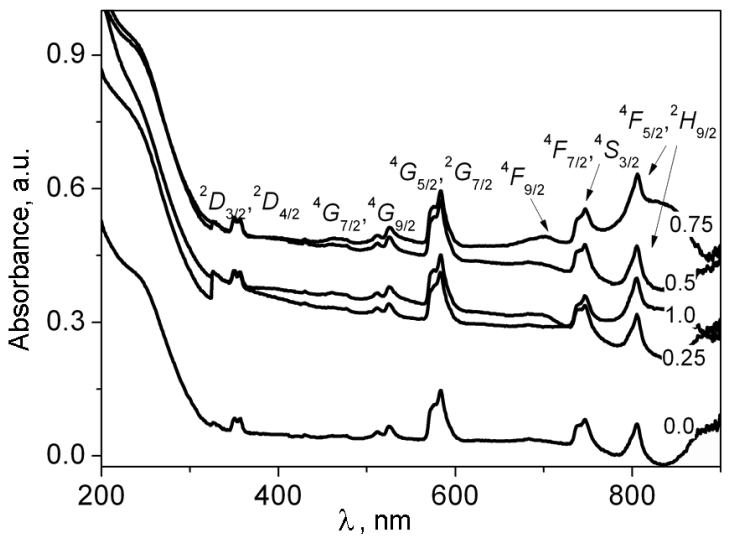

Fig. 1. UV-Vis spectra for the optic $\mathrm{Ba}_{1-x} \mathrm{Sr}_{x} \mathrm{gl}$ for $x=0.0,0.25,0.50,0.75,1.0$ and the assignment of peaks given alongside.

tion wavelength $1064 \mathrm{~nm}$. It can induce resonant two-photon absorption transitions into the band ${ }^{4} G_{9 / 2}$ with peak at about $525 \mathrm{~nm}$ with efficiency of the photoinduced absorption. The effect allows monitoring the structural modifications of the phosphate glasses produced by the Sr/Ba substitution via the laser radiation self-action through the $\mathrm{Nd}^{3+}$ resonant excitation.

\subsection{FTIR spectroscopy}

Normalized IR transmission spectra of the phosphate glass samples with corresponding characteristic vibrations are presented in Fig. 2. Considering the presence of oxygen atoms at the composition of nonphosphate groups (borates, silicates, and aluminates), the ratio of $P / O$ is found to about 3. This ratio corresponds to the composition of metaphosphates, indicating the predominance of tetrahedral $Q_{2}$ units as a structural motif of metaphosphate glasses 


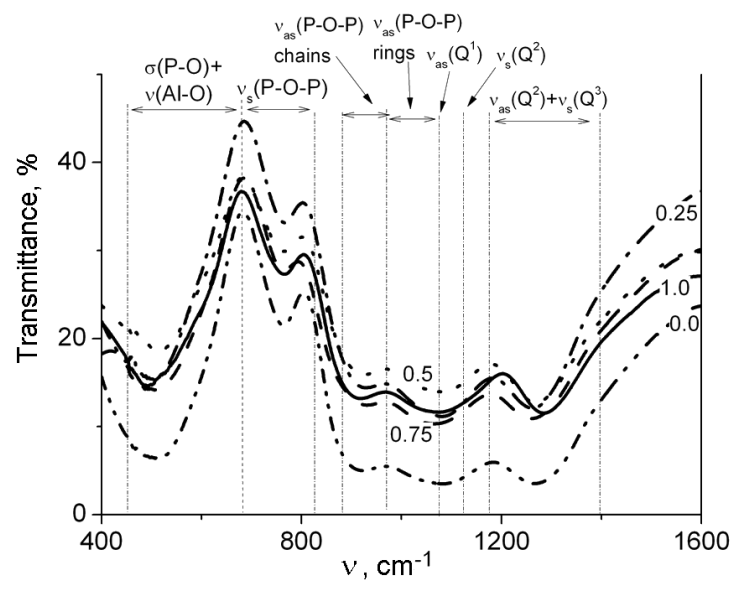

Fig. 2. IR spectra for the optic $\mathrm{Ba}_{1-x} \mathrm{Sr}_{x} \mathrm{gl}$ glasses with different $\mathrm{Sr} / \mathrm{Ba}$ content for $x=0.0$, $0.25,0.50,0.75,1.0$.

net [24, 25]. Since $Q_{2}$ unit has less amount of the terminal oxygen atoms versus the coordination number of strontium $\left(\mathrm{SrO}_{6}\right)$ and barium $\left(\mathrm{BaO}_{8}\right)$ ions in oxide glasses, the $\mathrm{Sr} / \mathrm{Ba}$ ions can coordinate oxygen ions via formation of bonds with oxygen ions of corresponding adjacent $Q_{2}$ units. Moreover, $\mathrm{Sr}$ and $\mathrm{Ba}$ atoms can not fill completely the oxygen coordinate environment that indicates the certain oxygen vacancies concentration that suggests to increase with the Ba content rise ( $x$ reduction) in the glass matrix. Modification of the optical properties depends on the possibilities of electronic detrapping, which is proportional to the number of related surface and internal oxygen vacancies.

Since the relative intensity of the bands at the replacement of the $\mathrm{Sr}$ for $\mathrm{Ba}$ and vise-versa is changed due to the change of the molar ratios of phosphate units to metal ions, so all the IR spectra are normalized to the molar absorptive coefficient of the media at the same concentration of adsorptive groups. The absorption in the range $430-1400 \mathrm{~cm}^{-1}$ corresponds to vibrations, in the most part, of terminal $Q_{1}, Q_{2}$, and $Q_{3}$ groups [24]. So, as can be seen from the Fig. 2, the highest absorption and thus the shortest length of the phosphate chain has the glass with $100 \%$ content of barium $(x=0.0)$. This fact can be explained by a stronger polarizability of the glass matrix that occurs due to the larger ionic radius of the $\mathrm{Ba}^{2+}$ ion versus the $\mathrm{Sr}^{2+}$ one. The $\mathrm{Ba}_{0.5} \mathrm{Sr}_{0.5} \mathrm{gl}$ demonstrates the lowest absorption that correlates with the metallicity criterion (see Table 1). Due to the long phosphate chains lengths in the phosphate glasses they serve

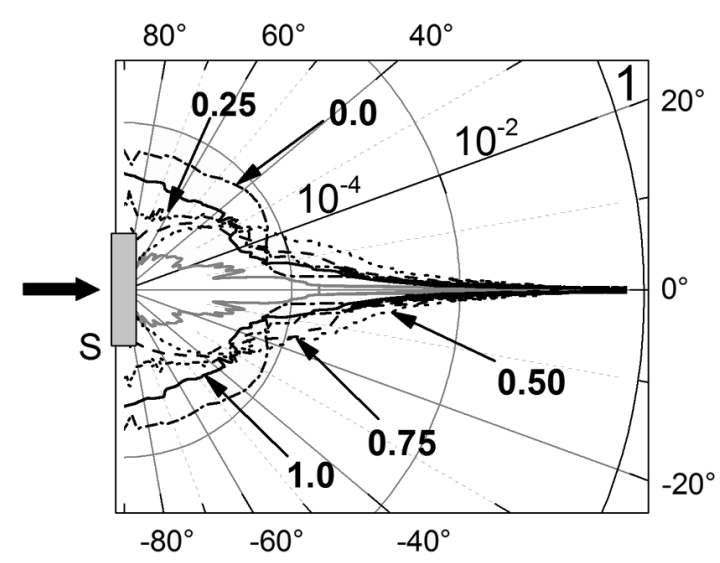

Fig. 3. The optical scattering indicatrices in forward hemisphere at $1064 \mathrm{~nm}$ for the optic $\mathrm{Ba}_{1-x} \mathrm{Sr}_{x} \mathrm{gl}$ glasses with different $\mathrm{Sr} / \mathrm{Ba}$ content for $x=0.0,0.25,0.50,0.75,1.0$. The grey curve corresponds to the freely propagating laser beam as a reference.

as the most asymmetric environment for the $\mathrm{Nd}^{3+}$ activator that causes the lowest ionicity of $\mathrm{Nd}-\mathrm{O}$ bonds. It was confirmed by the results of the UV-Vis absorption studies (see Table 2). For $\mathrm{Ba}_{0.5} \mathrm{Sr}_{0.5} \mathrm{gl}$ a number of oxygen vacancies should be the maximal due to the steric factor [25] that effects on the coordination/existence of long phosphate chains in a net.

\subsection{Optical scattering}

The optical scattering indicatrices of the studied laser glasses at $1064 \mathrm{~nm}$ are represented in Fig. 3. It is shown that the scattering of the glasses strongly depends on the Sr/Ba content. The calculated scattering losses into forward hemisphere and samples thickness $L$ are given in Table 2. It was shown that only the Sr-based and Ba-based glasses are characterized by the smallest scattering losses. The Sr/Ba substitution reveals the nonmonotonic variations of the scattering efficiency: the scattering losses

Table 2. The thicknesses $L$ and the scattering losses into forward hemisphere at $1064 \mathrm{~nm}$ for the optic glasses $\mathrm{Sr}_{x} \mathrm{Ba}_{1-x} \mathrm{gl}$ with different $\mathrm{Ba} / \mathrm{Sr}$ content

\begin{tabular}{|c|c|c||}
\hline$x$ & $L, \mathrm{~mm}$ & Scat.Losses, \% \\
\hline 0.0 & 1.82 & 2.5 \\
0.25 & 1.94 & 8.4 \\
0.50 & 2.00 & 12.6 \\
0.75 & 1.82 & 8.4 \\
1.0 & 1.76 & 5.2 \\
\hline
\end{tabular}



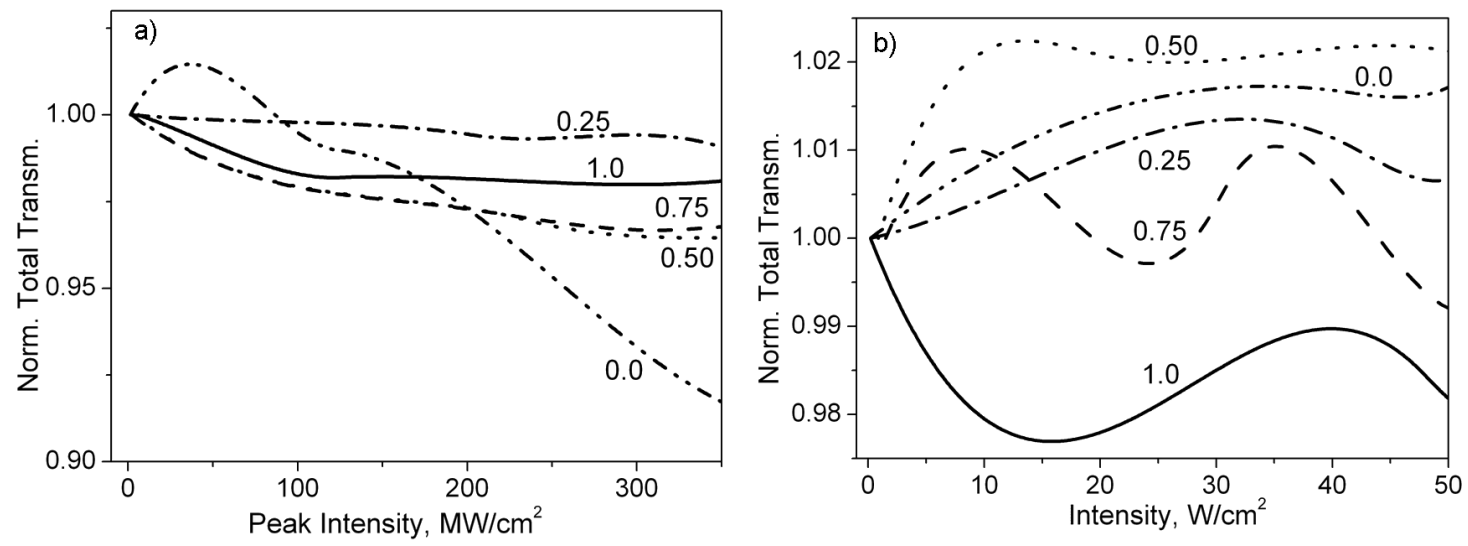

Fig. 4. The photoinduced variations of the normalized total transmittance in the pulsed (42 ps) (a), and $\mathrm{CW}$ - (b) excitation regimes at $1064 \mathrm{~nm}$ for the optic $\mathrm{Ba}_{1-x} \mathrm{Sr}_{x} \mathrm{gl}$ glasses with different $\mathrm{Sr} / \mathrm{Ba}$ content for $x=0.0,0.25,0.50,0.75$, and 1.0 .

are the highest for the $x=0.5(\sim 12.6 \%)$ and decreases for the other glasses. For the Sr/Ba content $x=0.25$ and $x=0.75$ the scattering losses is almost equal.

\subsection{Nonlinear optical characterization}

The photoinduced variations of the total transmittance of the phosphate laser glasses within the pulsed excitation regime are presented in Fig. 4a. Each experimental curve corresponds to the data acquisition for about 5000 laser shots. The typical error bar of the curves is about $\pm 1 \%$. It can be seen that the total transmittance of the glass with $100 \%$ of Ba significantly differs versus the others. It demonstrates the photoinduced bleaching at the peak intensity range $5-50 \mathrm{MW} / \mathrm{cm}^{2}$. For the higher peak intensities the process saturates and turns to efficient photodarkening effect with magnitude $\sim 10 \%$. For the samples that contain $\mathrm{Sr}$ the monotonic photoinduced darkening effect was observed with the saturation at about $100 \mathrm{MW} / \mathrm{cm}^{2}$. The efficiency of the process significantly depends on the Sr/Ba ratio. The almost total compensation of the pronounced photoinduced absorption variations was revealed for the $\mathrm{Ba}_{0.75} \mathrm{Sr}_{0.25} \mathrm{gl}$ sample.

For the case of the $\mathrm{CW}$ laser excitation the photoinduced variations of the total transmittance are presented in Fig. 4b. It was shown that only for the degenerate case $x=1$ the glass demonstrates the photodarkening effect that turns to photobleaching one at about $15 \mathrm{~W} / \mathrm{cm}^{2}$. For the samples that contain $\mathrm{Ba}$ the photoinduced bleaching was observed. The process saturates and turns to photodarkening at the following intensity magnitudes that rises with

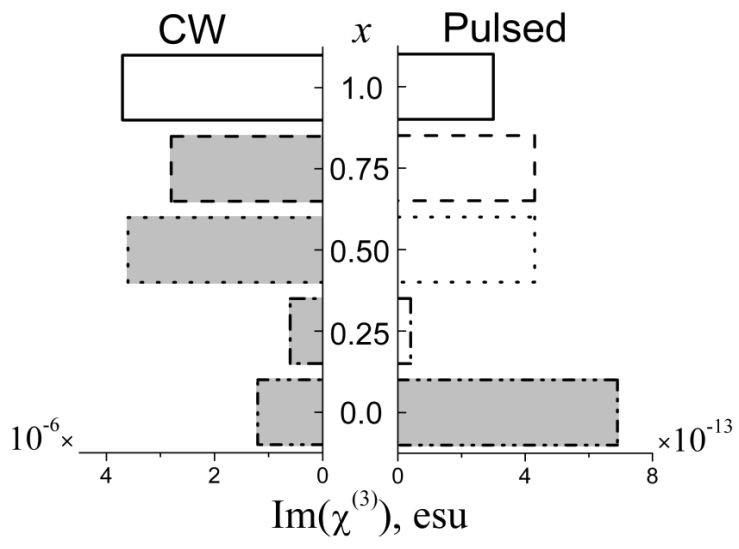

Fig. 5. The magnitudes of the imaginary part of the cubic NLO susceptibility in CW and pulsed excitation regimes for the optic $\mathrm{Ba}_{1-x} \mathrm{Sr}_{x} \mathrm{gl}$ glasses with $x=0.0,0.25,0.50$, 0.75 , and 1.0. The transparent bars indicate the photoinduced darkening effect $(\Delta \alpha>0)$, patterned - the photoinduced bleaching one $(\Delta \alpha<0)$.

the reduction of parameter $x$ given in brackets: $\sim 8.0 \mathrm{~W} / \mathrm{cm}^{2}(0.75) ; \sim 13.3 \mathrm{~W} / \mathrm{cm}^{2}(0.5)$; $\sim 32.4 \mathrm{~W} / \mathrm{cm}^{2}(0.25)$, and $\sim 34.3 \mathrm{~W} / \mathrm{cm}^{2}(0.0)$.

From the obtained total transmittance dependences the magnitudes of the imaginary part of the cubic NLO susceptibility $\operatorname{Im}\left(\chi^{(3)}\right)$ were estimated. The comparison of the results for the cases of the pulsed and CW laser excitations are represented in Fig. 5 as a bar diagram. The transparent bars indicate the photoinduced darkening effect $(\Delta \alpha>0)$, patterned - the photoinduced bleaching one $(\Delta \alpha<0)$.

It was shown that for $\mathrm{CW}$ excitation the substitution of $\mathrm{Sr}$ for $\mathrm{Ba}$ results in $\operatorname{Im}\left(\chi^{(3)}\right)$ 
reduction and the sign turn. In the case of the pulsed excitation the increase of the $\mathrm{Ba}$ content reveals the $\operatorname{Im}\left(\chi^{(3)}\right)$ rise except the glass with $x=0.25$.

The lowest magnitudes of the photoinduced bleaching/absorption efficiencies $\left|\operatorname{Im}\left(\chi^{(3)}\right)\right| \sim 6 \cdot 10^{-7} / 4 \cdot 10^{-14}$ esu for CW/pulsed excitation regime was revealed for $\mathrm{Ba}_{0.75} \mathrm{Sr}_{0.25} \mathrm{gl}$ that indicates it to be the most optimal against the laser beam distortion inside the media.

The observed sensitivity of the laser radiation self-action effects to the Sr/Ba ratio in the phosphate glass indicates the applied approach to be promising for their structure diagnostics. The proposed technique can be applied for the oxygen stoichiometry diagnostics for laser phosphate glasses due to the resonant multiphoton excitation of $\mathrm{Nd}^{3+}$ ions at $1064 \mathrm{~nm}$.

\section{Conclusions}

The characterization of the optic phosphate glasses $\mathrm{Ba}_{1-x} \mathrm{Sr}_{x} \mathrm{gl}$ with different contain of Sr/Ba ions was performed by UV-VIS spectral, FTIR, elastic scattering indicatrices and NLO response analyses. Advanced methods for purification of initial reagents were applied. The effect of the Sr/Ba ratio on the glass structure was observed. It was shown that the positions and the form of UV-Vis spectra peaks of the studied optic glasses are similar and almost independent on the minor $\mathrm{Nd}^{3+}$ volume concentration variations with the $\mathrm{Ba} / \mathrm{Sr}$ ratio.

The optical scattering indicatrices analysis revealed the nonmonotonic variations of the scattering efficiency versus the $\mathrm{Sr} / \mathrm{Ba}$ ratio: the scattering losses $\sim 12.6 \%$ are the highest for the $\mathrm{Ba}_{0.5} \mathrm{Sr}_{0.5} \mathrm{gl}$ that corresponds to the peak oxygen vacancies concentration due to the steric factor. The glasses with symmetric substitution levels $x=0.25$ and 0.75 demonstrate the similar level of extinction losses $~ 8.4 \%$.

The absorptive NLO response under the excitation of $\mathrm{CW}$ and pulsed laser radiation at $1064 \mathrm{~nm}$ were analyzed. It was shown that the photoinduced absorption/bleaching variations are strongly dependent on the ratio of $\mathrm{Sr} / \mathrm{Ba}$ in the phosphate glasses. The observed effects were attributed to the resonant two-photon absorption into $\mathrm{Nd}^{3+}$ band ${ }^{4} G_{9 / 2}$. The efficiency of the transition can be controlled by the local field deterioration due to the oxygen vacancies impact in the vicinity of the $\mathrm{Nd}$ ion. Except the degenerate cases at $x=0.0$ and 1.0 the $\mathrm{Ba}_{0.5} \mathrm{Sr}_{0.5} \mathrm{gl}$ reveals the most efficient photoinduced absorption/bleaching efficiency within pulsed/CW laser excitation at $1064 \mathrm{~nm}$ correspondingly. In degenerate cases for both excitation regimes we have observed photobleaching $\left(x=0, \operatorname{Im}\left(\chi^{(3)}\right)<0\right)$ and photoinduced absorption $\left(x=1, \operatorname{Im}\left(\chi^{(3)}\right)<0\right)$ at the initial range of the laser intensities. For the rest of the samples the absorptive NLO response has opposite signs within laser pulsed and CW excitation (see Fig. 5).

The lowest magnitudes of the photoinduced bleaching/absorption efficiencies $\left|\operatorname{Im}\left(\chi^{(3)}\right)\right| \sim 6 \cdot 10^{-7} / 4 \cdot 10^{-14}$ esu for $\mathrm{CW} /$ pulsed excitation regime was revealed for $\mathrm{Ba}_{0.75} \mathrm{Sr}_{0.25} \mathrm{gl}$ that indicates it to be the most optimal against the laser beam distortion inside the media. For the $x=0.25$ composition it was also obtained UV-vis range absorption and elastic scattering reduction. The mentioned optical properties improvement was achieved by both the substitution level choice modification and the purification of the initial reagents.

On the basis of the obtained results we suggest a high potential of the application of the CW and pulsed laser radiation selfaction effects at wavelength $1064 \mathrm{~nm}$ within elastic scattering indicatrices analysis for the testing of oxygen vacancies concentration in the phosphate laser glasses for the application in the field of quantum and optoelectronics.

Acknowledgments. The work was partially supported by joint NASU-NASB project No.04-02-15, and NASU project B/166.

\section{References}

1. E.U. Patent 0,218,135 (1987).

2. U.S. Patent 3,979,322 (1976).

3. R.F. Patent 2,426,701 (2011).

4. U.S. Patent 5526369A (1996).

5. U.S. Patent 20,060,128,549 (2008).

6. U.S. Patent 7,435,695B2 (2008).

7. U.S. Patent 4,075,120A (1978).

8. R.D.Shannon, R.X.Fischer, Phys.Rev.B, 73, 235111 (2006).

9. G.Walter, U.Hoppe, A.Barz et al., J.NonCryst. Solids., 263-264, 48 (2000).

10. A.Paleari, V.N.Sigaev, N.V.Golubev et al., Mater. Chem. Phys., 128, 12 (2011).

11. V.Ya.Gayvoronsky, L.A.Golovan, M.A.Kopylovsky et al., Quant. Electron. 41, 257 (2011).

12. A.V.Uklein, A.S.Popov, V.V.Multian et al., NanoScale Res. Lett., 10, 102 (2015).

13. V.E.Diyuk, A.N.Zaderko, K.I.Veselovska, V.V.Lisnyak, J.Thermal Anal.Calorim., 120, 1665 (2015).

14. ASTM D854-14 (2014). 
15. I.V.Dimitrov, S.Sakka, J.Appl.Phys., 79, 1736 (1996).

16. J.A.Duffy, M.D.Ingram, J.Am.Chem.Soc., 93, 6448 (1971).

17. L.S.Dent-Glasser, J.A.Duffy, J.Chem.Soc., Dalton Trans., 10, 2323 (1987).

18. J.A.Duffy, J.Phys.Chem., 110, 13245 (2006).

19. Y.Waseda, J.M.Toguri, The Structure and Properties of Oxide Melts: Application of Basic Science to Metallurgical Processing, World Scientific Publishers, Singapore (1998).

20. V.Ya.Gayvoronsky, A.S.Popov, M.S.Brodyn et al., in: Nanocomposites, Nanophotonics, Nanobiotechnology and Applications, Edition: Springer Proceedings in Physics 156, Springer, Cham-Heidelberg-NY (2015), p.147.
21. V.Ya.Gayvoronsky, M.A.Kopylovsky, M.S.Brodyn et al., in: Nanomaterials Imaging Techniques, Surface Studies and Applications, Edition: Springer Proceedings in Physics 146, Springer, New York, USA (2013), p.349.

22. A.B.P.Lever, Inorganic Electronic Spectroscopy. Studies in Physical and Theoretical Chemistry, Elsevier, Amsterdam (1986).

23. J.J.Garcia Sole, L.E.Bausa, D.Jaque, An Introduction to the Optical Spectroscopy of Inorganic Solids, Wiley, Chichester (2005).

24. L.L.Velli, C.P.E.Varsamis, E.I.Kamitsos et al., Phys.Chem. Glasses, 46, 178 (2005).

25. H.Takebe, Y.Nageno, K.Morinaga, J.Am. Ceram.Soc. 77, 2132 (1994). 